\title{
Diverse manganese(II)-oxidizing bacteria are prevalent in drinking water systems
}

Daniel N. Marcus ${ }^{1,2}$, Ameet Pinto 3 , Karthik Anantharaman ${ }^{1}$, Steven A. Ruberg 4 , Eva L. Kramer ${ }^{1}$, Lutgarde Raskin ${ }^{2}$, and Gregory J. Dick ${ }^{*}$.

\footnotetext{
1Department of Earth and Environmental Science, University of Michigan, Ann
} Arbor, MI, USA

2Department of Civil and Environmental Engineering, University of Michigan, Ann Arbor, MI, USA

${ }^{3}$ Department of Civil and Environmental Engineering, Northeastern University, Boston, MA, USA

${ }^{4}$ Great Lakes Environmental Research Laboratory, National Oceanic and

Atmospheric Administration, Ann Arbor, MI, USA

*Corresponding author.

Email:gdick@umich.edu

Telephone \#: 1-734-763-3228

Fax \#: 1-734-763-4690

Address: 2534 C.C. Little Building, 1100 North University Ave, Ann Arbor MI, 481091005 USA

\footnotetext{
Originality-Significance Statement

Microorganisms play an important role in mediating drinking water quality throughout water systems, from source to distribution. Here we identify a number of new manganese-oxidizing bacteria and find that they are abundant and perhaps even dominant members of microbial communities in in drinking water systems. Given the exceptional chemical reactivity of biogenic Mn oxides, these results suggest that these organisms may affect water quality in terms of aesthetic appearance, speciation of metals, and oxidation of organic and inorganic compounds.
}

This is the author manuscript accepted for publication and has undergone full peer review but has not been through the copyediting, typesetting, pagination and proofreading process, which may lead to differences between this version and the Version record. Please cite this article as doi:10.1111/ 1758-2229.12508. 


\section{Summary}

Manganese (Mn) oxides are highly reactive minerals that influence the speciation, mobility, bioavailability, and toxicity of a wide variety of organic and inorganic compounds. Although Mn(II)-oxidizing bacteria are known to catalyze the formation of Mn oxides, little is known about the organisms responsible for $\mathrm{Mn}$ oxidation in situ, especially in engineered environments. Mn(II)-oxidizing bacteria

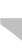
are important in drinking water systems, including in biofiltration and water distribution systems. Here we used cultivation dependent and independent approaches to investigate Mn(II)-oxidizing bacteria in drinking water sources, a treatment plant and associated distribution system. We isolated 29 strains of $\mathrm{Mn}(\mathrm{II})$-oxidizing bacteria and found that highly similar 16S rRNA gene sequences were present in all culture-independent datasets and dominant in the studied drinking water treatment plant. These results highlight a potentially important role for Mn(II)-oxidizing bacteria in drinking water systems, where biogenic Mn oxides may affect water quality in terms of aesthetic appearance, speciation of metals, and oxidation of organic and inorganic compounds. Deciphering the ecology of these organisms and the factors that regulate their Mn(II)-oxidizing activity could yield important insights into how microbial communities influence the quality of drinking water. 


\section{Introduction}

The presence of manganese (Mn) in source waters used for drinking water (DW) production is a common concern, primarily due to the impact of Mn on the aesthetic quality of finished water (Kohl \& Medlar, 2006). Mn is regulated by the

U.S. Environmental Protection Agency at a non-enforceable secondary maximum contaminant level (MCL) of $0.05 \mathrm{mg} / \mathrm{L}$ (EPA, 2013). Regardless of the possible direct effects of Mn on human health (Bouchard et al., 2011; Khan et al., 2012), the presence of Mn oxides in DW can strongly alter other aspects of water chemistry (Tebo et al., 2004), thus they may indirectly influence the quality of DW.

Mn oxides can rapidly oxidize other metals and metalloids (metal(loid)s hereafter), affecting their speciation, mobility, and toxicity. For example, Mn oxides can convert highly toxic trivalent arsenic into the less acutely toxic pentavalent form (Tournassat et al., 2002). In addition to their strong redox activity, Mn oxides have a high capacity for cation exchange, sorption, and co-precipitation of metal(loid)s

(Tebo et al., 2004). Thus, they can sequester and immobilize a wide array of heavy metal(loid)s and have been used for this purpose in DW (Driehaus et al., 1995; Bajpai \& Chaudhuri, 1999). Mn oxides contribute to the decomposition of complex organic matter (Sunda \& Kieber, 1994) and effectively degrade some endocrine disruptors (de Rudder et al., 2004; Furgal et al., 2015). Mn oxides often have detoxifying effects on pollutants, however they can also catalyze reactions that increase the toxicity of some metal(loid)s. Particularly relevant to DW is chromium (Cr), which is rapidly oxidized by biogenic Mn oxides from a relatively harmless 
form, $\mathrm{Cr}(\mathrm{III})$, to a highly mobile, bioavailable, and carcinogenic form, $\mathrm{Cr}$ (VI) (Murray et al., 2005; Costa \& Klein, 2006).

Under oxic and circumneutral pH conditions, the abiotic oxidation of aqueous Mn(II) to solid Mn oxides is thermodynamically favorable but kinetically slow relative to bacterially-mediated Mn(II) oxidation (Tebo et al., 2004). Thus, the oxidation of Mn(II) to Mn(III) and Mn(IV) in the environment is believed to be largely catalyzed by bacteria (Tebo et al., 2007). In contrast, Mn removal during DW treatment is commonly achieved through abiotic oxidation of dissolved Mn(II) with chlorine or ozone followed by filtration of particulate and colloidal Mn oxides (Kohl \& Medlar, 2006). Biological Mn removal as an alternative to traditional chemical processes is increasing in popularity (Tekerlekopoulou et al., 2013) and removal efficiencies of over $98 \%$ have been demonstrated (Tekerlekopoulou et al., 2013; Hoyland et al., 2014). The documented presence of Mn(II)-oxidizing microorganisms in DW systems that are not specifically operated for biological Mn oxidation (Sly et al., 1988; Cerrato et al., 2010) raises the question of their broader role and utility in DW systems.

Characterizing the role of microorganisms in mediating the formation of Mn oxides in complex systems, including DW systems, is challenging due to the extensive diversity of Mn(II)-oxidizing bacteria and mechanisms by which Mn(II) oxidation can be catalyzed. Distantly related bacteria from phyla such as Firmicutes, Actinobacteria and Proteobacteria can oxidize Mn(II) (Tebo et al., 2005), and the ability to oxidize $\mathrm{Mn}$ (II) is not always conserved between phylogenetically closely related bacteria (Dick et al., 2008; Anderson et al., 2009). 
The presence and role of Mn(II)-oxidizing bacteria in DW systems has been investigated only to a limited extent. In some cases, well characterized Mn(II)oxidizing groups such as Pseudomonas, Bacillus and Leptothrix have been identified in DW systems (Katsoyiannis \& Zouboulis, 2004; Burger et al., 2008; Cerrato et al., 2010; Farkas et al., 2013), but it remains unclear if they are abundant and to what extent they contribute to Mn cycling. Despite recent advances in DNA sequencing technologies and in understanding the molecular mechanisms of bacterial Mn(II) oxidation, identifying Mn(II)-oxidizing bacteria with culture-independent methods remains challenging since there are no known universal molecular markers for Mn(II) oxidation. Therefore, cultivation remains an important means of identifying $\mathrm{Mn}(\mathrm{II}$ )-oxidizing bacteria. This poses a significant hurdle in identifying environmentally relevant Mn(II)-oxidizing bacteria as only a small portion of community members are typically able to be cultivated (Staley \& Konopka, 1985). However, for those Mn(II)-oxidizing bacteria that are amenable to laboratory growth, high throughput DNA sequencing can be used to elucidate their abundance (or the abundance of closely related taxa) within complex microbial consortia. In this study, we cultured and characterized Mn(II)-oxidizing bacteria from one DW treatment plant and two surface water sources used for DW production. We describe several novel Mn(II)-oxidizing bacteria, and found that some were abundant members of the analyzed DW treatment system's microbial communities, suggesting a high capacity for biological Mn(II) oxidation in DW systems.

\section{Results}




\section{Isolation and phylogenetic characterization of Mn(II)-oxidizing bacteria}

We isolated Mn(II)-oxidizing bacteria from surface sediments of Lake Erie and the Huron River (Ann Arbor, MI), and from the DW treatment and distribution system (DWDS) in Ann Arbor, MI. A total of 29 Mn(II)-oxidizing bacteria were isolated, and 21 of the $16 \mathrm{~S}$ rRNA gene sequences obtained were unique (shared a maximum of $99 \%$ sequence identity) (Table 1 ). The isolates are taxonomically diverse and fall within the high and low GC gram-positive bacteria (Actinobacteria and Bacillaceae, respectively) and Alpha-, Beta-, and Gammaproteobacteria. Many of these groups were previously known to harbor Mn(II)-oxidizing bacteria (Tebo et al., 2005). However, as discussed below in more detail, we also identified bacteria in three genera not previously associated with Mn(II) oxidation (Table 1).

\section{[TABLE 1]}

Phylogenetic analysis of 16S rRNA gene sequences was used to investigate relationships between the Mn(II)-oxidizing bacteria found in this study and those previously reported in the literature. The majority of Firmicutes and Pseudomonas (Phylum: Proteobacteria, Class: Gammaproteobacteria) isolates fell into lineages that contain previously identified Mn(II)-oxidizing bacteria. Four of the unique Firmicutes isolates fell within the genus Bacillus; one clustered with organisms isolated from marine sediments that oxidize $\mathrm{Mn}$ (II) as metabolically dormant spores (Francis \& Tebo, 2002; Dick et al., 2006), two were closely related to Bacillus muralis, and one to Bacillus niacini. The remaining two phylogenetically distinct Firmicutes isolates clustered tightly with Lysinibacillus (Supporting Information Fig. S1), which are known to oxidize Mn(II) (Johnson et al., 2011). 
Two of the Mn(II)-oxidizing Pseudomonas isolates clustered with two separate clades of Mn(II)-oxidizing bacteria isolated from cave deposits (Carmichael et al., 2013). Two isolates were in a clade with Pseudomonas chlororaphis, and Pseudomonas extremorientalis; the latter was isolated from a DW reservoir (Ivanova et al., 2002) (Supporting Information Fig. 2). All of the Mn(II)-oxidizing

Pseudomonas isolates have $97-98 \% 16$ S rRNA gene sequence identity to Pse Pseduomonas putida strains Mn-B1 and GB-1. Strain Mn-B1 was isolated from a Mnencrusted DW pipe in Germany (Schweisfurth, 1973) and both organisms have long been used as model systems for studying bacterial Mn(II) oxidation (Caspi et al., 1998; Geszvain \& Tebo, 2010).

Mn(II)-oxidizing bacteria were identified in three genera of Alphaproteobacteria, including Afipia, Bosea, and Reyranella (Fig. 1). To our knowledge, Reyranella has not been implicated in Mn(II) oxidation previously. Mn(II)-oxidizing Afipia strains have previously been found in rock varnishes from the Atacama desert in Chile (Kuhlman et al., 2008) and New Mexico (Northup et al., 2010). A single Mn(II)-oxidizing Bosea culture ("RM1") was obtained from a stream containing abundant Mn oxides in the U.K. and was subsequently used to evaluate Mn(II) removal in experimental reactors (Mariner et al., 2008). Alphaproteobacteria are commonly capable of Mn(II) oxidation, and many of these isolates or their close relatives have been observed in DW systems (Fig. 1).

\section{[FIGURE 1]}

Three phylogenetically unique Mn(II)-oxidizing Betaproteobacteria were isolated belonging to the genus Hydrogenophaga, which had not previously been 
known to oxidize Mn(II) (Fig. 2). From the order Burkholderiales, three genera of Mn(II)-oxidizing bacteria have previously been reported: Burkholderia, Caldimonas, and Leptothrix, all of which have previously been found in DW sources or systems (Zanetti et al., 2000; Laseke, 2006; de Vet et al., 2009; Laseke et al., 2010). Mn(II)oxidizing Actinobacteria clustered within the genera Mycobacterium, Arthrobacter, Agromyces, and Microbacterium (Supporting Information Fig. S3). To our knowledge, Mn(II) oxidation within the genus Agromyces is novel.

\section{[FIGURE 2]}

\section{Abundance of Mn(II)-oxidizing taxa in bacterial communities of DW systems}

To investigate the abundance of Mn(II)-oxidizing bacteria in DW associated microbial communities, 16S rRNA gene sequences retrieved from isolates were compared to culture-independent $16 \mathrm{~S}$ rRNA gene datasets from the DW system in Ann Arbor, MI. The majority of the Ann Arbor data was obtained by 454 GS-FLX sequencing of the V4-V5 region (Pinto et al., 2014). However, two Sanger sequenced clone libraries were created and analyzed to corroborate the findings from 454 amplicon sequencing over additional 16S rRNA gene positions. Given the disparity of sequence lengths between 454 amplicons and assembled near full-length Sanger sequences, an in-silico comparison of sequence similarites for the V4-V5 region and near full-length $16 \mathrm{~S}$ rRNA gene sequences was conducted using Silva references. A description of the method can be found in Supporting Information along with obtained results (Supporting Information Table S1). Briefly, we found that 
phylogenetic conservation between the V4-V5 region and the near full-length $16 \mathrm{~S}$ rRNA gene sequence varied by phylogenetic group.

At a BLASTN threshold of $99 \%$ identity over $280 \mathrm{bp}, 12$ of the 21 phylogenetically unique Mn(II)-oxidizing isolates matched at least $0.5 \%$ of recovered 454 bacterial sequences in at least one of the seven Ann Arbor DW system locations (Supporting Information Tables S2 \& S3). The two most abundant bacterial genera were Hydrogenophaga and Bosea. Hydrogenophaga sp. K42-1A, which was isolated from Huron River surface sediments, was especially abundant in the filter and filter effluent, where in some samples it represented approximately half of the community sequences recovered (Fig. 3A). The abundance of

Hydrogenophaga sp. K42-1A was much lower in source water (river \& well) and was intermediate in the filter influent, reservoir and distribution system samples. Two additional Hydrogenophaga isolates satisfied the $0.5 \%$ community abundance threshold specified above, but were consistently much less abundant than Hydrogenophaga sp. K42-1A (Supporting Information Table S3).

\section{[FIGURE 3]}

Bosea sp. T10-3D-2C, which was isolated from a filter influent sample, was the second most abundant isolate throughout the DW system recovered in the culture independent dataset (Fig. 3B). In contrast with Hydrogenophaga sp. K42-1A, Bosea sp. T10-3D-2C was most abundant in the distribution system. The abundance of other isolates recovered in this study that made up at least $0.5 \%$ of the total community in one sample can be found in Supporting Information Table S3. 
Two clone libraries were created to validate the trends observed from 454 community data. Five of 49 near full-length $16 \mathrm{~S}$ rRNA gene sequences obtained from multiple pooled Ann Arbor DWDS samples matched Mn(II)-oxidizing isolates with BLASTN cutoffs of $97 \%$ ID over $1200 \mathrm{bp}$. All five hits matched sequences of isolates from either the Ann Arbor DW system or source water. This includes four BLASTN matches to Hyrogenophaga spp. isolated from Huron River sediments and the Ann Arbor DW treatment plant intake well and one BLASTN match to Reyranella sp. T2-6AA isolated from the Ann Arbor filters. The results confirmed the presence of environmental sequences that matched Hydrogenophaga sp. K42-1A with high sequence specificity over more than just the V4-V5 region of the $16 \mathrm{~S}$ rRNA gene.

A single Ann Arbor filter sample was selected for an additional clone library on the basis of the elevated abundance (53\%) of sequences closely related to Hydrogenophaga sp. K42-1A in the 454 amplicon data. This library yielded 13 partial 16S rRNA gene sequence clones (out of a total of 51) with at least 97\% sequence identity over 800 bp to isolates obtained from the Ann Arbor DW system. Eleven of these clones matched Hydrogenophaga spp. (K42-1A, T6-1B, and T5-5DA2), one matched only Hydrogenophaga spp. K42-1A and T5-5DA-2 and one matched Bosea sp. T10-3D-2C. Thus, both Ann Arbor clone libraries showed sizeable proportions of sequences closely related to Hydrogenophaga isolates, corroborating the 454 GS-FLX derived abundance estimates.

Hydrogenophaga sp. K42-1A obtained from an Ann Arbor DW source is closely related to one of the most dominant operational taxonomic units (OTUs) in the DW system (Pinto et al. 2012; Pinto et al., 2014), raising the question of whether 
such organisms deposit Mn oxides in DW systems. Hydrogenophaga species are commonly identified as abundant members of DW microbial communities, thus their impact on Mn cycling and associated chemical processes could be widespread and substantial. In bulk water collected from a model, non-chlorinated DWDS in Denmark, nearly $20 \%$ of all isolates obtained were Hydrogenophaga, and it was the single most abundant taxon identified by almost a factor of two (Martiny et al., 2005). In Greece, Hydrogenophaga amounted to approximately $8 \%$ of all clones recovered from a DWDS (Kormas et al., 2010). In a comparison of microbial communities from GAC filters in multiple DW treatment plants, approximately $14 \%$ of all isolates obtained were Hydrogenophaga (Magic-Knezev et al., 2009).

Consistent with our findings, Hydrogenophaga has been documented as a dominant community member in numerous DW communities around the world. From source waters through the various stages of DW treatment, there is an increased water abundance of taxa associated with Mn(II) oxidation, such as Hydrogenophaga (Fig. 3), consistent with major changes in community structure due to treatment processes (Pinto et al., 2012). The Ann Arbor DW treatment plant employs ozonation for disinfection prior to filtration (Pinto et al., 2012). This process oxidizes natural organic matter into simpler compounds (Becker \& O'Melia, 2001) that are more bioavailable. Hence, organisms that survive the highly selective ozonation process could rapidly proliferate in an environment of reduced competition and with readily biodegradable compounds available.

In this study, we isolated Mn(II)-oxidizing bacteria from a conventional DW system and showed that some of the taxonomic groups are novel and some are 
abundant in communities of bacteria within a DW system. Although previous studies have isolated Mn(II)-oxidizing bacteria from DW systems (Schweisfurth, 1973; Sly et al., 1988; Sly et al., 1990; Cerrato et al., 2010), they have not reported that such bacteria can be abundant members of DW bacterial communities. These results contrast those of other environments where bacterial Mn(II) oxidation is prevalent but cultured Mn(II)-oxidizing bacteria were at such low abundance that they remained undetected with culture-independent methods (Dick \& Tebo, 2010). Indeed, few studies have cultured Mn(II)-oxidizing bacteria that were abundant members of their source communities (Bräuer et al., 2011).

\section{Conclusions}

Overall, our results have several important implications for understanding bacterial Mn(II) oxidation and its impact on the chemistry of DW. First, the observed abundance Mn(II)-oxidizing bacteria in DW systems suggests that biogenic Mn oxides produced by these organisms could influence DW quality. Highly reactive biogenic Mn oxides (i) alter the speciation, toxicity, and mobility of metal(loid)s such as chromium and arsenic and (ii) degrade refractory organic compounds into labile forms, which may influence bacterial regrowth in DW distribution systems (Escobar \& Randall, 2001). Second, our results suggest that DW treatment strongly selects for taxa capable of Mn(II) oxidation, potentially amplifying their role in chemical transformations such as those indicated above. Third, the mechanisms of Mn(II) oxidation has not been studied in many of the Mn(II)-oxidizing bacteria isolated here, including the dominant community member Hydrogenophaga. This 
presents an opportunity to investigate bacterial Mn(II) oxidation both in pure culture and in situ within environmental communities. An increased understanding of the physiological function and environmental controls of bacterial Mn(II)

oxidation may help guide strategies for optimizing microbial community function to improve DW quality.

\section{Acknowledgements}

We thank Larry Sanford from the Ann Arbor DW treatment plant for

assistance with sampling.

\section{References}

Anderson, C. R., Dick, G. J., Chu, M. L., Cho, J. C., Davis, R. E., Bräuer, S. L., \& Tebo, B. M. (2009) Aurantimonas manganoxydans, sp nov and Aurantimonas litoralis, sp nov.: $\mathrm{Mn}$ (II) Oxidizing Representatives of a Globally Distributed Clade of alpha-Proteobacteria from the Order Rhizobiales. Geomicrobiol J 26: 189-198.

Bajpai, S., \& Chaudhuri, M. (1999) Removal of arsenic from ground water by manganese dioxide-coated sand. J Environ Eng 125: 782-784.

Becker, W. C., \& O'Melia, C. R. (2001) Ozone: its effect on coagulation and filtration. Water Sci Technol 1: 81-88.

Bouchard, M. F., Sauve, S., Barbeau, B., Legrand, M., Brodeur, M. E., Bouffard, T., et al. (2011) Intellectual Impairment in School-Age Children Exposed to Manganese from Drinking Water. Environ Health Perspect 119: 138-143.

Bräuer, S. L., Adams, C., Kranzler, K., Murphy, D., Xu, M., Zuber, P., et al. (2011) Culturable Rhodobacter and Shewanella species are abundant in estuarine turbidity maxima of the Columbia River. Environ Microbiol 13: 589-603.

Burger, M. S., Krentz, C. A., Mercer, S. S., \& Gagnon, G. A. (2008) Manganese removal and occurrence of manganese oxidizing bacteria in full-scale biofilters. J Water Supply Res Technol-AQUA 57: 351-359. 
Carmichael, M. J., Carmichael, S. K., Santelli, C. M., Strom, A., \& Bräuer, S. L. (2013) $\mathrm{Mn}$ (II)-oxidizing bacteria are abundant and environmentally relevant members of ferromanganese deposits in caves of the Upper Tennessee River Basin. Geomicrobiol J 30: $779-800$.

Caspi, R., Tebo, B. M., \& Haygood, M. G. (1998) c-Type cytochromes and manganese oxidation in Pseudomonas putida MnB1. Appl Environ Microbiol 64: 3549-3555.

Cerrato, J. M., Falkinham, J. O., III, Dietrich, A. M., Knocke, W. R., McKinney, C. W., \& Pruden, A. (2010) Manganese-oxidizing and -reducing microorganisms isolated from biofilms in chlorinated drinking water systems. Water Res 44: 3935-3945.

Costa, M., \& Klein, C. B. (2006) Toxicity and carcinogenicity of chromium compounds in humans. Crit Rev Toxicol 36: 155-163.

de Rudder, J., Van de Wiele, T., Dhooge, W., Comhaire, F., \& Verstraete, W. (2004) Advanced water treatment with manganese oxide for the removal of 17 alphaethynylestradiol (EE2). Water Res 38: 184-192.

de Vet, W., Dinkla, I. J. T., Muyzer, G., Rietveld, L. C., \& van Loosdrecht, M. C. M. (2009) Molecular characterization of microbial populations in groundwater sources and sand filters for drinking water production. Water Res 43: 182-194.

Dick, G. J., Lee, Y. E., \& Tebo, B. M. (2006) Manganese(II)-oxidizing bacillus spores in Guaymas Basin hydrothermal sediments and plumes. Appl Environ Microbiol 72: 31843190.

Dick, G. J., Podell, S., Johnson, H. A., Rivera-Espinoza, Y., Bernier-Latmani, R., McCarthy, J. K., et al. (2008) Genomic insights into Mn(II) oxidation by the marine alphaproteobacterium Aurantimonas sp strain SI85-9A1. Appl Environ Microbiol 74: 2646-2658.

Dick, G. J., \& Tebo, B. M. (2010) Microbial diversity and biogeochemistry of the Guaymas Basin deep-sea hydrothermal plume. Environ Microbiol 12: 1334-1347.

Driehaus, W., Seith, R., \& Jekel, M. (1995) Oxidation of arsenate(iii) with manganese oxides in water-treatment. Water Res 29: 297-305.

EPA. (2013) Secondary drinking water regulations: guidance for nuisance chemicals. [WWW document]. URL http://water.epa.gov/drink/contaminants/secondarystandards.cfm

Escobar, I. C., \& Randall, A. A. (2001) Case study: Ozonation and distribution system biostability. J Amer Water Works Assoc 93: 77-89. 
Farkas, A., Dragan-Bularda, M., Muntean, V., Ciataras, D., \& Tigan, S. (2013) Microbial activity in drinking water-associated biofilms. Cent Eur J Biol 8: 201-214.

Francis, C. A., \& Tebo, B. M. (2002) Enzymatic Manganese(II) oxidation by metabolically dormant spores of diverse Bacillus species. Appl Environ Microbiol 68: 874-880.

Furgal, K. M., Meyer, R. L., \& Bester, K. (2015) Removing selected steroid hormones, biocides and pharmaceuticals from water by means of biogenic manganese oxide nanoparticles in situ at ppb levels. Chemosphere 136: 321-326.

Geszvain, K., \& Tebo, B. M. (2010) Identification of a two-component regulatory pathway essential for $\mathrm{Mn}(\mathrm{II})$ oxidation in pseudomonas putida gb-1. Appl Environ Microbiol 76: 1224-1231.

Hoyland, V. W., Knocke, W. R., Falkinham III, J. O., Pruden, A., \& Singh, G. (2014) Effect of drinking water treatment process parameters on biological removal of manganese from surface water. Water Res 66: 31-39.

Ivanova, E. P., Gorshkova, N. M., Sawabe, T., Hayashi, K., Kalinovskaya, N. I., Lysenko, A. M., et al. (2002) Pseudomonas extremorientalis sp nov., isolated from a drinking water reservoir. Int J Syst Evol Microbiol 52: 2113-2120.

Johnson, K.W., Carmichael, M.J., McDonald, W., Rose, N., Pitchford, J., Karatan, E., \& Bräuer, S.L. (2011). Increased abundance of Gallionella spp., Leptothrix spp., and total bacteria in response to enhanced $\mathrm{Mn}$ and Fe concentrations in a distrubed southern appalachian high elevation wetland. Geomicrobiology Journal 29: 124-138.

Katsoyiannis, I. A., \& Zouboulis, A. I. (2004) Biological treatment of Mn(II) and Fe(II) containing groundwater: kinetic considerations and product characterization. Water Res 38: 1922-1932.

Khan, K., Wasserman, G. A., Liu, X. H., Ahmed, E., Parvez, F., Slavkovich, V., et al. (2012) Manganese exposure from drinking water and children's academic achievement. Neurotoxicology 33: 91-97.

Kohl, P., \& Medlar, S. (2006) Occurrence of manganese in drinking water and manganese control. Colorado, USA: American Water Works Association.

Kormas, K. A., Neofitou, C., Pachiadaki, M., \& Koufostathi, E. (2010) Changes of the bacterial assemblages throughout an urban drinking water distribution system. Environ Monit Assess 165: 27-38.

Kuhlman, K. R., Venkat, P., La Duc, M. T., Kuhlman, G. M., \& McKay, C. P. (2008) Evidence of a microbial community associated with rock varnish at Yungay, Atacama Desert, Chile. J Geophys Res Biogeosci 113: G04022. 
Laseke, I. (2006) Identification and characterization of bacterial communities in warm groundwater aquifers. Masters thesis, University of Cincinnati.

Laseke, I., Korte, J., Lamendella, R., Kaneshiro, E. S., Marciano-Cabral, F., \& Oerther, D. B. (2010) Identification of Naegleria fowleri in warm ground water aquifers. J Environ Qual 39: 147-153.

Magic-Knezev, A., Wullings, B., \& Van der Kooij, D. (2009) Polaromonas and Hydrogenophaga species are the predominant bacteria cultured from granular activated carbon filters in water treatment. J Appl Microbiol 107: 1457-1467.

Mariner, R., Johnson, D. B., \& Hallberg, K. B. (2008) Characterisation of an attenuation system for the remediation of $\mathrm{Mn}$ (II) contaminated waters. Hydrometallurgy 94: 100104.

Martiny, A. C., Albrechtsen, H. J., Arvin, E., \& Molin, S. (2005) Identification of bacteria in biofilm and bulk water samples from a nonchlorinated model drinking water distribution system: Detection of a large nitrite-oxidizing population associated with Nitrospira spp. Appl Environ Microbiol 71: 8611-8617.

Murray, K. J., Mozafarzadeh, M. L., \& Tebo, B. M. (2005) Cr(III) oxidation and Cr toxicity in cultures of the manganese(II)-oxidizing Pseudomonas putida strain GB-1.

Geomicrobiol J 22: 151-159.

Northup, D. E., Snider, J. R., Spilde, M. N., Porter, M. L., van de Kamp, J. L., Boston, P. J., et al. (2010) Diversity of rock varnish bacterial communities from Black Canyon, New Mexico. J Geophys Res Biogeosci 115:

Pinto, A. J., Xi, C. W., \& Raskin, L. (2012) Bacterial community structure in the drinking water microbiome is governed by filtration processes. Environ Sci Technol 46: 88518859.

Pinto, A. J., Schroeder, J., Lunn, M., Sloan, W., \& Raskin, L. (2014) Spatial-temporal survey and occupancy-abundance modeling to predict bacterial community dynamics in the drinking water microbiome. Mbio 5: e01135-14.

Schweisfurth, R. (1973) Manganoxydierende bakterien. i. isolierung und bestimmung einiger stamme von manganbakterien. Z Allg Mikrobiol 13: 341-347.

Sly, L. I., Arunpairojana, V., \& Hodgkinson, M. C. (1988) Pedomicrobium-manganicum from drinking-water distribution-systems with manganese-related dirty water problems. Syst Appl Microbiol 11: 75-84.

Sly, L. I., Hodgkinson, M. C., \& Arunpairojana, V. (1990) Deposition of manganese in a drinking-water distribution-system. Appl Environ Microbiol 56: 628-639. 
Staley, J. T. \& Konopka, A. (1985) Measurement of in situ activities of nonphotosynthetic microorganisms in aquatic and terrestrial habitats. Annu Rev Microbiol 39: 321-346.

Stamatakis, A. (2014) RAxML version 8: a tool for phylogenetic analysis and post-analysis of large phylogenies. Bioinformatics 30(9): 1312-1313.

Sunda, W. G., \& Kieber, D. J. (1994) Oxidation of humic substances by manganese oxides yields low-molecular-weight organic substrates. Nature 367: 62-64.

Tebo, B. M., Bargar, J. R., Clement, B. G., Dick, G. J., Murray, K. J., Parker, D., et al. (2004) Biogenic manganese oxides: Properties and mechanisms of formation. Annu Rev Earth Planet Sci 32: 287-328.

Tebo, B. M., Johnson, H. A., McCarthy, J. K., \& Templeton, A. S. (2005) Geomicrobiology of manganese(II) oxidation. Trends Microbiol 13: 421-428.

Tebo, B.M., Clement, B.G., and Dick, G.J. (2007) Biotransformations of manganese. In Manual of Environmental Microbiology. Hurst, C.J., Crawford, R.L., Garland, J.L., Lipson, D.A., Mills, A.L., and Stetzenbach, L.D. (eds). Washington, DC, USA: ASM Press, pp.1223-1238.

Tekerlekopoulou, A. G., Pavlou, S., \& Vayenas, D. V. (2013) Removal of ammonium, iron and manganese from potable water in biofiltration units: a review. J. Chem. Technol. Biotechnol 88(5): 751-773.

Tournassat, C., Charlet, L., Bosbach, D., \& Manceau, A. (2002) Arsenic(III) oxidation by birnessite and precipitation of manganese(II) arsenate. Environ Sci Technol 36: 493-500.

Zanetti, F., De Luca, G., \& Stampi, S. (2000) Recovery of Burkholderia pseudomallei and B-cepacia from drinking water. Int J Food Microbiol 59: 67-72. 


\section{Figure legends}

\section{Figure 1}

Maxmimum likelihood phylogenetic tree of $16 \mathrm{~S}$ rRNA gene sequences for the class Alphaproteobacteria. Sequences in bold are from this study. Trees were bootstrapped 1000 times using RAxML (Stamatakis, 2014) with the GTRGAMMA model of nucleotide substitution. The dashed branch to the outgroup was condensed.

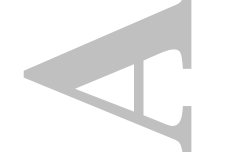

\section{Figure 2}

Maxmimum likelihood phylogenetic tree of $16 \mathrm{~S}$ rRNA gene sequences for the class Betaproteobacteria. Sequences in bold are from this study. Trees were bootstrapped 1000 times using RAxML (Stamatakis, 2014) with the GTRGAMMA r model of nucleotide substitution. The dashed branch to the outgroup was condensed. $\star 1$ : one additional isolate with $100 \%$ sequence identity was obtained from the AA DW treatment plant.

\section{Figure 3}

Box and whisker relative abundance plot of pyro tag sequences from Ann Arbor DW system satisfying a 99\% identity threshold over at least 280 bp when BLASTN aligned against (A) Hydrogenophaga sp. K42-1A and (B) Bosea sp. T10-3D-2C. 


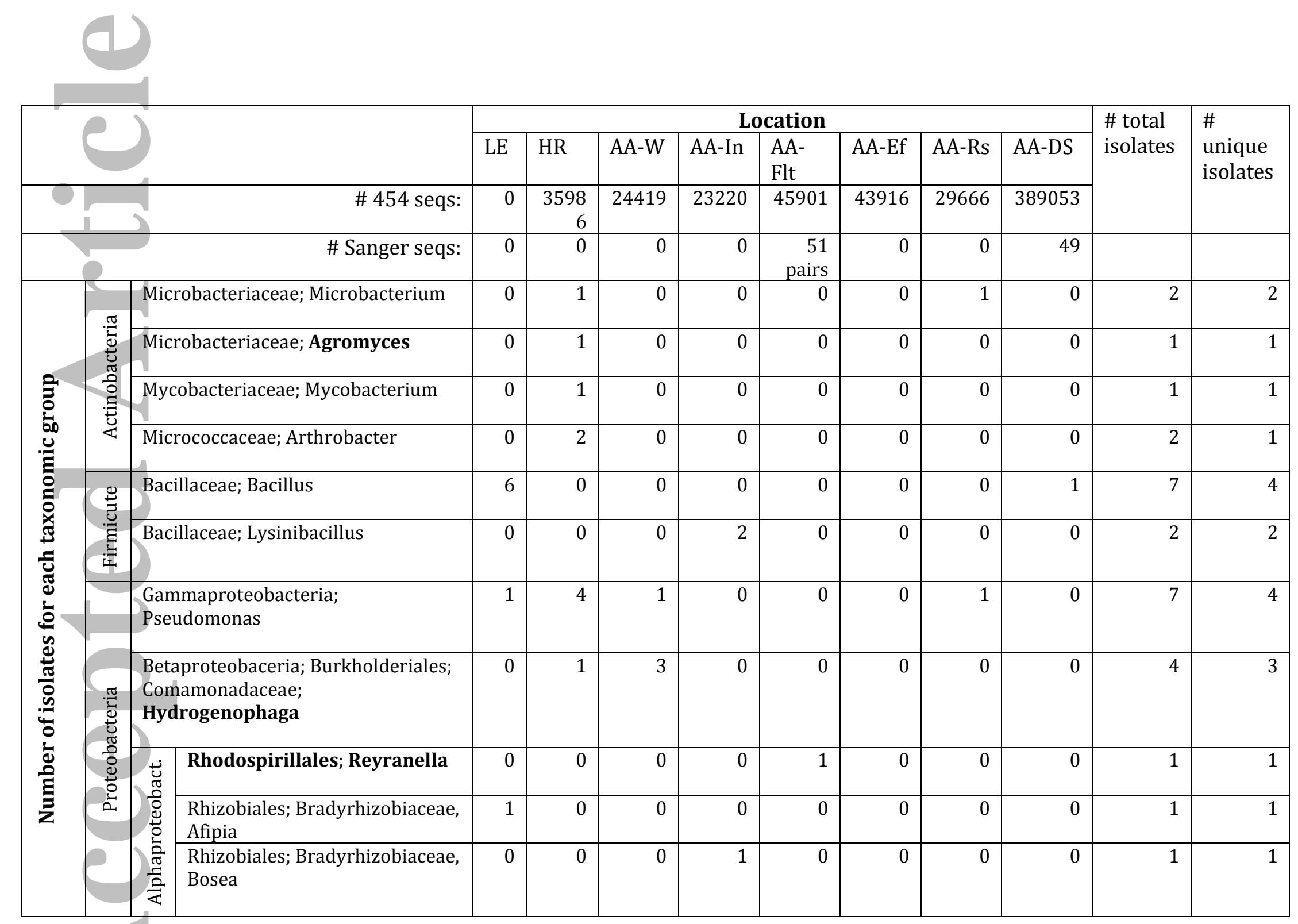


Table 1. Sequencing effort and number of Mn(II)-oxidizing bacteria isolated. Bolded taxa are taxonomically novel Mn(II) oxidizers. Phylogenetically equivalent isolates were $100 \%$ identical to one another. AA, Ann Arbor; DWTP1, Drinking Water Treatment Plant Filters; LE, Lake Erie; HR, Huron River; W, Well; In, Filter Influent; Flt, Filter; Ef, Filter Effluent; Rs, Reservoir; DS, Distribution System; \# tot. isol., Number of Total Isolates; \# uni. isol., Number of Unique Isolates.

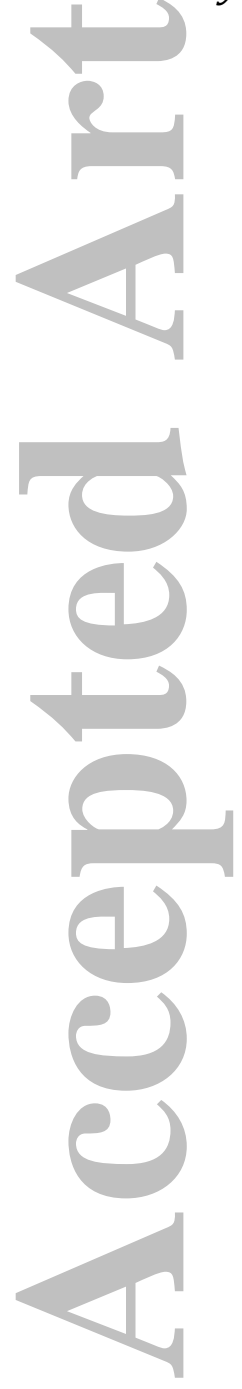




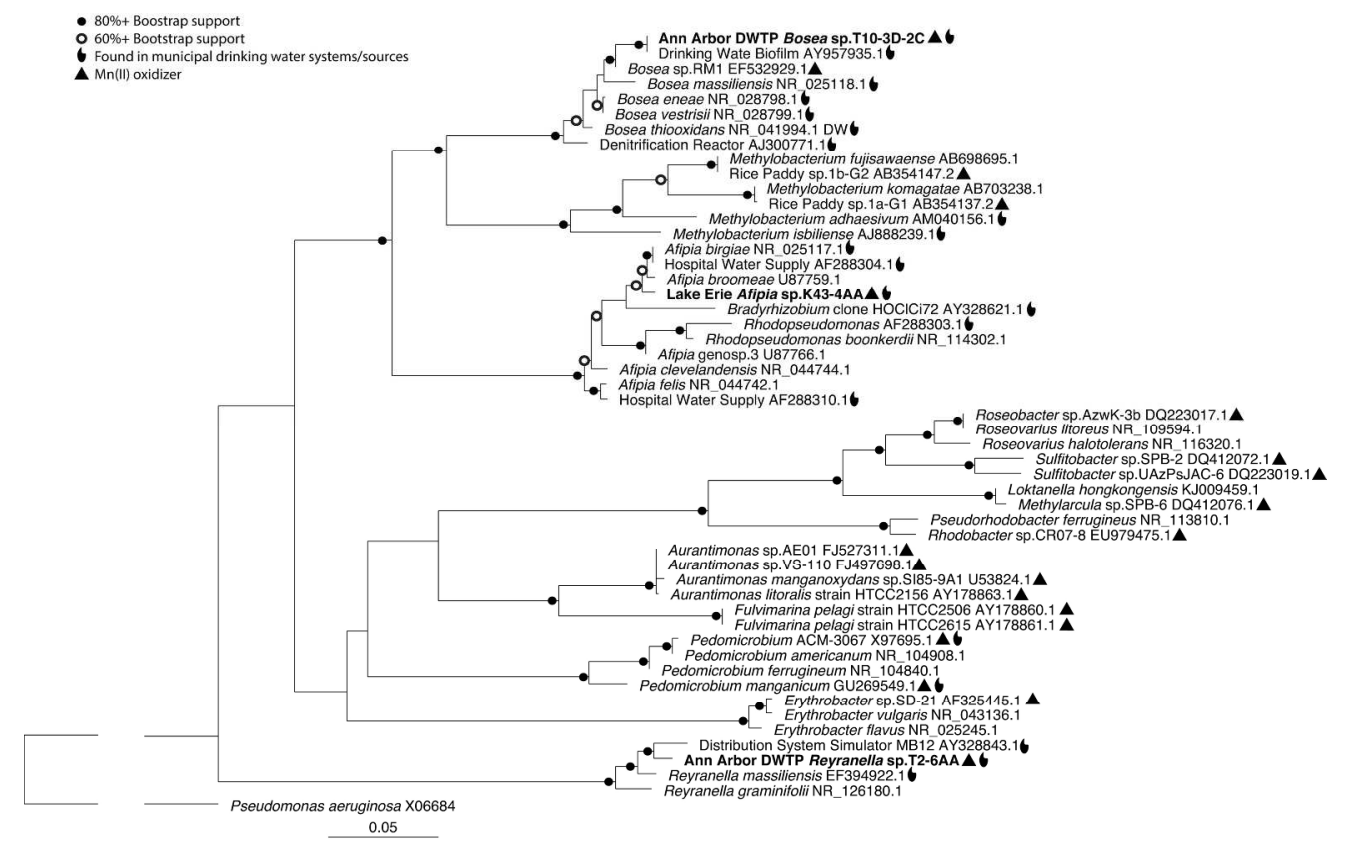

Figure 1. Maxmimum likelihood phylogenetic tree of $16 \mathrm{~S}$ rRNA gene sequences for the class Alphaproteobacteria. Sequences in bold are from this study. Trees were bootstrapped 1000 times using RAXML (Stamatakis, 2014) with the GTRGAMMA model of nucleotide substitution. The dashed branch to the outgroup was condensed.

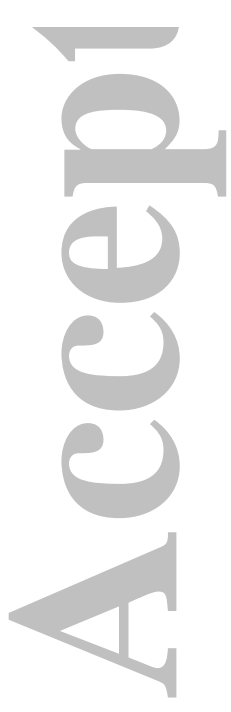

$237 \times 150 \mathrm{~mm}(300 \times 300$ DPI $)$ 


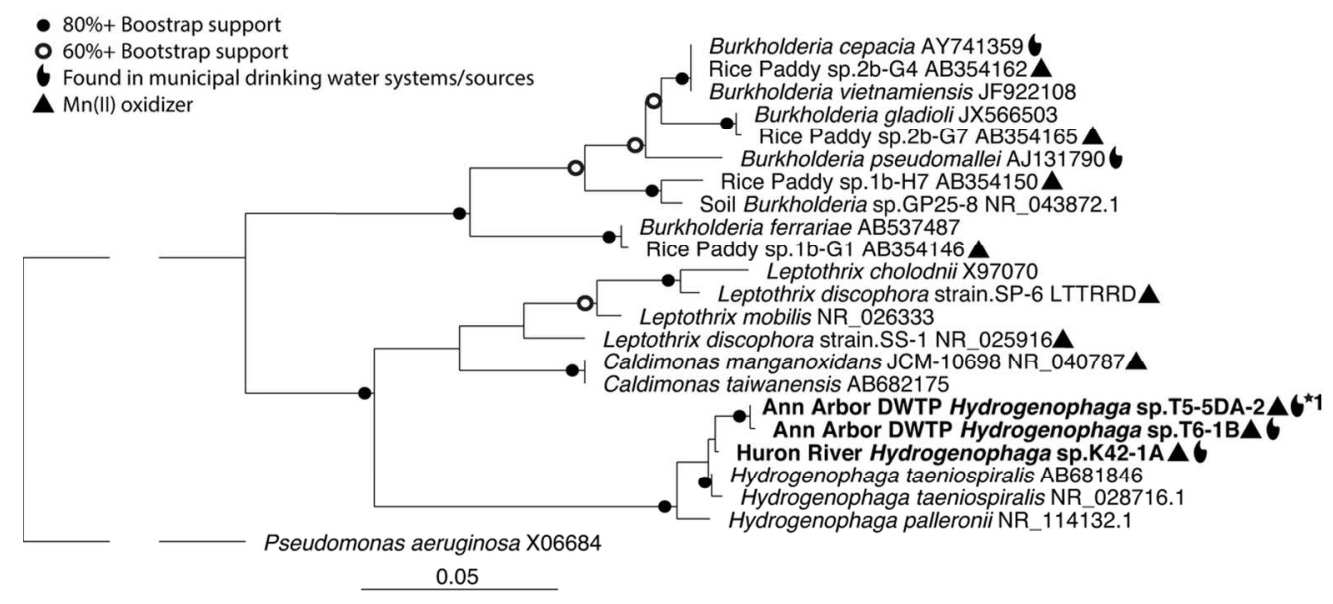

Figure 2. Maxmimum likelihood phylogenetic tree of $16 \mathrm{~S}$ rRNA gene sequences for the class Betaproteobacteria. Sequences in bold are from this study. Trees were bootstrapped 1000 times using RAxML (Stamatakis, 2014) with the GTRGAMMA model of nucleotide substitution. The dashed branch to the outgroup was condensed. $* 1$ : one additional isolate with $100 \%$ sequence identity was obtained from the AA DW treatment plant.

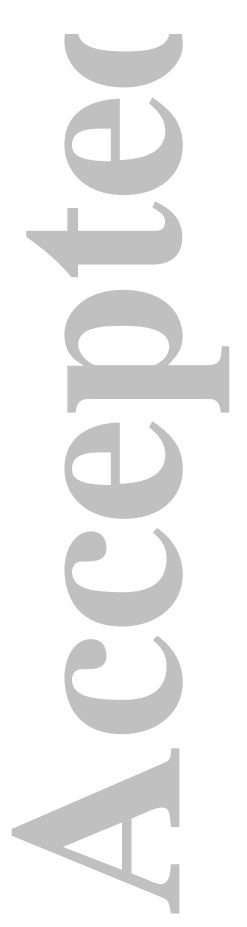

$111 \times 49 \mathrm{~mm}(300 \times 300 \mathrm{DPI})$ 

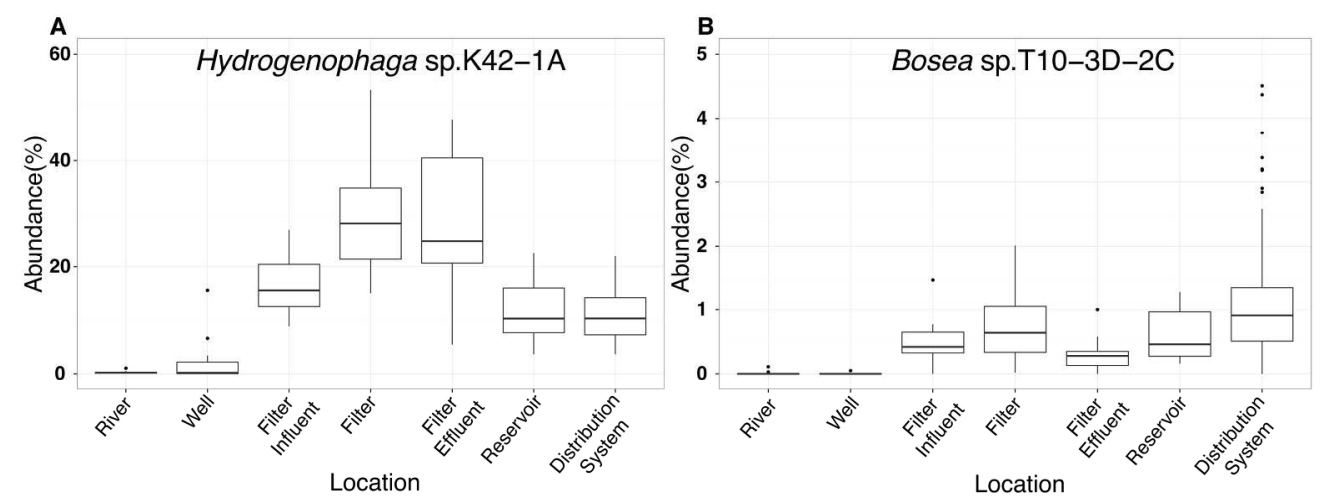

Figure 3. Box and whisker relative abundance plot of pyro tag sequences from Ann Arbor DW system satisfying a $99 \%$ identity threshold over at least 280 bp when BLASTN aligned against (A) Hydrogenophaga sp. K42-1A and (B) Bosea sp. T10-3D-2C.

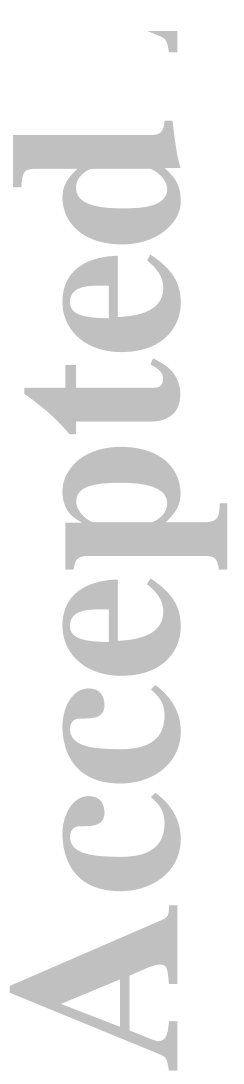

$218 \times 83 \mathrm{~mm}(300 \times 300 \mathrm{DPI})$ 